\title{
Analytic and Dynamic Secretory Profile of Patient-Derived Cytokine-Induced Killer Cells
}

\author{
Giulia Mesiano, ${ }_{1}^{1 *}$ Roberta Zini, ${ }^{3, *}$ Giulia Montagner ${ }_{,}^{4}$ Nicoletta Bianchi, ${ }^{4}$ Rossella Manfredini, ${ }^{3}$ Antonella \\ Chillemi, ${ }^{5}$ Massimo Aglietta, ${ }^{1,2}$ Giovanni Grignani, ${ }^{1,2}$ Ilaria Lampronti, ${ }^{4}$ Erika Fiorino, ${ }^{2}$ Fabio Malavasi, ${ }^{5}$ \\ Dario Sangiolo, ${ }^{1,2}$ Roberto Gambari, ${ }^{4}$ and Davide Ferrari ${ }^{4,6}$
}

${ }^{1}$ Division of Medical Oncology, Experimental Cell Therapy, Candiolo Cancer Institute, FPO-IRCCS, Candiolo, Torino, Italy, ${ }^{2}$ Department of Oncology, University of Torino, Candiolo, Torino, Italy, ${ }^{3}$ Centre for Regenerative Medicine "Stefano Ferrari," Department of Life Sciences, University of Modena and Reggio Emilia, Modena, Italy, ${ }^{4}$ Department of Life Science and Biotechnology, Sections of Microbiology and Applied Pathology; Biochemistry and Molecular Biology, University of Ferrara, Ferrara, Italy, and ${ }^{5}$ Laboratory of Immunogenetics and CeRMS, Department of Medical Sciences, University of Torino, Torino, Italy

\begin{abstract}
Adoptive immunotherapy with cytokine induced killer (CIK) cells has shown antitumor activity against several kinds of cancer in preclinical models and clinical trials. CIK cells are a subset of ex vivo expanded T lymphocytes with T-NK phenotype and MHCunrestricted antitumor activity. The literature provides scant information on cytokines, chemokines and growth factors secreted by CIK cells. Therefore, we investigated the secretory profile of CIK cells generated from tumor patients. The secretome analysis was performed at specific time points ( $d$ l, $d 14$ and d 21) of CIK cell expansion. Mature CIK cells (d 21) produce a great variety of interleukins and secreted proteins that can be divided into three groups based on their secretion quantity: high (interleukin (IL)-13, regulated on activation normal T cell expressed and secreted (RANTES) chemokine, MIP-1 $\alpha$ and 1 13), medium (IL-1Ra, IL-5, IL-8, IL-10, IL-17, IP-10, INF- $\gamma$, vascular endothelial growth factor (VEGF) and granulocyte-macrophage colony-stimulating factor (GM-CSF)) and low (IL-1 $\beta$, IL-4, IL-6, IL-7, IL-9, IL-12, IL-15, eotaxin, platelet-derived growth factor-bb, basic fibroblast growth factor, G-CSF and monocyte chemoattractant protein (MCP)-1). Moreover, comparing peripheral blood mononuclear cells (PBMCs) (d 1) and mature CIK cells (d 14 and 21) secretomes, we observed that IL-5, IL-10, IL-13, GM-CSF and VEGF were greatly upregulated, while IL-1 $\beta$, IL-6, IL-8, IL-15, IL-17, eotaxin, MCP-1 and RANTES were downregulated. We also performed a gene expression profile analysis of patient-derived CIK cells, showing that mRNA for the different cytokines and secreted proteins was modulated during PBMC-to-CIK differentiation. We highlight previously unknown secretory properties and provide, for the first time, a comprehensive molecular characterization of CIK cells. Our findings provide a rationale to explore the functional implications and possible therapeutic modulation of CIK secretome.
\end{abstract}

Online address: http://www.molmed.org

doi: $10.2119 / \mathrm{molmed} .2017 .00084$

\section{INTRODUCTION}

Adoptive immunotherapy with cytokine-induced cells holds promise as a new therapeutic approach in the setting of metastatic solid tumors refractory to standard treatments. Cytokine-induced killer (CIK) cells are heterogeneous ex vivo expanded T lymphocytes with mixed T-NK phenotype and endowed with wide MHC-unrestricted antitumor activity against both solid and hematologic malignancies (1-7). CIK cells can be easily expanded ex vivo up to clinical relevant rates from circulating peripheral blood mononuclear cells (PBMCs), according to a standard protocol involving

\section{*Authors equally contributed.}

Address correspondence to Davide Ferrari, Department of Life Science and Biotechnology, Sections of Microbiology and Applied Pathology; Biochemistry and Molecular Biology, University of Ferrara, Ferrara, Italy. Phone: + 39-0532-455406; E-mail: dfr@unife.it. Submitted May 15, 2017; Accepted for Publication August 1, 2017;

Published Online (www.molmed.org) August 9, 2017.

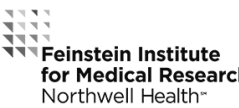

timed stimulation with interferon (IFN)- $\gamma$ (d 0), anti-CD3 moAb OKT3 (d 1) and interleukin (IL)-2 (from d 1 to the end) (8-10). The MHC-independent tumor-killing ability of CIK cells favors their possible clinical translation, as, in theory, they could be applied to all patients regardless their human leukocyte antigen haplotype. CIK cells have a T-NK mixed phenotype with variable rates of $\mathrm{CD}^{+} \mathrm{CD}^{2} 6^{+}$cells, considered mainly responsible for the antitumor activity $(1,11,12)$. CIK cells express some activating receptors shared with natural killer (NK) cells such as NKG2D, DNAX accessory molecule-1 (DNAM-1) and low levels of NKp30, while they do not express NKp44 and NKp46, inhibitory killer immunoglobulin-like 
receptors NKG2A and CD94 (13). The antitumor activity of CIK cells is mainly due to the NKG2D receptor intensely expressed on the membrane of CIK cells. The main ligands recognized by NKG2D are MHC class I-related molecules A and B (MIC A/B) and members of the unique long 16-binding proteins, stress-inducible proteins expressed by tumor cells of various origin (3,4,14-18). Recent clinical trials support their initial activity and excellent safety profile in challenging settings such as lung, renal, liver, breast and gastrointestinal cancers (19).

It is known that CIK cells have a predominant Th1 phenotype, with reported secretion of IFN- $\gamma$ and tumor necrosis factor (TNF)- $\alpha(20,21)$, which are involved in regulating innate and adaptive immunities. The other positive regulatory cytokines that are secreted by CIK cells are IL-2 and IL-4 $(20,21)$.

Comprehensive information on the secretory activity of CIK cells is limited and needs to be more deeply explored to improve our knowledge of CIK cell biology and possible clinical applications. Investigation of CIK cell secretome can provide novel insights into its physiological mechanisms as well as a better understanding of immunological processes in this context. CIK cell performance is positively or negatively modulated by both cell-to-cell interactions and soluble factors secreted by CIK cells themselves or other cells. T regulatory lymphocytes (Tregs) have been shown to impair CIK cell activity. It has been demonstrated that depletion of Tregs before starting the $e x$ vivo culture improved CIK cell proliferation and tumor-killing activity (22). These effects were at least in part attributed to TGF-beta1 and glucocorticoid-induced tumor necrosis factor receptor (22). We hypothesize that other plasma membrane molecules or soluble factors have a role in modulation of CIK cell performance. It has been reported that IL-10 suppresses CIK cell activity and the co-culture of CIK cells with DC can reverse its effect (23).

In this study we explored the comprehensive secretory activity of patientderived CIK cells, at both the protein and
mRNA level. Furthermore, we conducted a dynamic analysis to highlight possible variations of different factors (cytokines, chemokines and growth factors) during the ex vivo expansion of CIK cells.

\section{MATERIALS AND METHODS}

\section{Ex Vivo Expansion and Phenotype Characterization of CIK Cells}

CIK cells were expanded from peripheral blood collected from five patients with histologically confirmed gastrointestinal stromal tumors (GISTs) at the Candiolo Cancer Institute, Fondazione del Piemonte per L'Oncologia-IRCCS. All individuals provided informed consent for blood donation according to a protocol approved by the internal review board and ethics committee. As control for the cytokines secretion analysis, we also generated CIK cells from five healthy donors. Cryopreserved PBMCs were seeded at a concentration of $2 \times 10^{6}$ cells / $\mathrm{mL}$ according to the standard protocol $(8,9)$, including $21 \mathrm{~d}$ of culture in RPMI1640 medium (Gibco BRL Life Technologies Italia, Monza, Italy) supplemented with 10\% fetal bovine serum (Sigma Aldrich, Milan, Italy), $100 \mathrm{U} / \mathrm{mL}$ penicillin and $100 \mathrm{U} / \mathrm{mL}$ streptomycin (Gibco BRL Life Technologies Italia) at $37^{\circ} \mathrm{C}$ and $5 \%$ $\mathrm{CO}_{2}$, with the timed addition of IFN- $\gamma$ (1000 U/mL on d 0), Ab anti-CD3 OKT3 (50 ng/mL on d 1) and IL-2 (300 U/mL on 1 up to the end, refreshing the medium every 2-3 d) (all factors are from Miltenyi Biotec, Calderara di Reno, Bologna, Italy). At d 0, a small amount of each PBMC culture $\left(7 \times 10^{6}\right)$ was seeded at the same concentration and culture conditions $\left(2 \times 10^{6}\right.$ cells $/ \mathrm{mL}$ in RPMI-1640 medium with $10 \%$ fetal bovine serum, $100 \mathrm{U} / \mathrm{mL}$ penicillin and streptomycin at $37^{\circ} \mathrm{C}$ and $5 \% \mathrm{CO}_{2}$ ) but without the addition of INF- $\gamma$. Aliquots of culture medium $(4.5 \mathrm{~mL})$ and $3 \times 10^{6}$ of PBMCs were collected at $\mathrm{d} 1$ for quantification of cytokines and RNA extraction, respectively. Culture medium was centrifuged to precipitate floating cells and stored at $-30^{\circ} \mathrm{C}$, while PBMCs were collected in Invitrogen $^{\mathrm{TM}} \mathrm{TRIzol}^{\mathrm{TM}}$ (Thermo Fisher Scientific,
Milan, Italy) and stored at $-80^{\circ} \mathrm{C}$. The same procedure was repeated for each CIK cell culture at d 14 and 21 .

The final expansion rate calculated on both bulk CIK cells and the CD ${ }^{+} \mathrm{CD} 56^{+}$ subset was determined. Phenotype of CIK cells was weekly analyzed starting from $\mathrm{d} 0$ by standard flow cytometric assay. The following monoclonal antibodies (mAbs) were used: CD3-FITC, CD4-PE, CD56-APC, CD8 ${ }^{-} \mathrm{PE}$ and CD314-APC (anti-NKG2D) (all mAbs were from Miltenyi Biotec). The Miltenyi Biotec Treg Detection kit (CD4/CD25/ Foxp3) (APC) was used to detect T regulatory cells within CIK cultures at d 14 and 21. Labeled cells were read on FACS CyAn ADP (Beckman Coulter, Cassina De' Pecchi, Milan, Italy) and analyzed using Summit software.

\section{Quantification of Cytokines and CIK Cell Secretome}

Cytokines released in culture medium by PBMCs ( $d$ 1, absence of INF- $\gamma$ ) and CIK cells (d 14 and 21) were measured by Bio-Plex cytokine assay (Bio-Rad Laboratories, Hercules, CA, USA) as described elsewhere (24). The Bio-Plex cytokine assay is designed for multiplexed quantitative measurement of different cytokines in a single well using as little as $50 \mu \mathrm{L}$ of supernatants collected at three time points. To perform the experiments, we used premixed multiplex beads of the Bio-Plex human cytokine Human 27-Plex Panel (Bio-Rad Laboratories), which included 27 secreted proteins: cytokines, chemokines and growth factors (IL-1 $\beta$, IL-1Ra, IL-2, IL-4, IL-5, IL-6, IL-7, IL-8, IL-9, IL-10, IL-12 p70, IL-13, IL-15, IL-17, fibroblast growth factor [FGF]-basic, eotaxin, granulocyte colony-stimulating factor [G-CSF], granulocyte-macrophage colony-stimulating factor [GM-CSF], IFN- $\gamma$, IP-10, monocyte chemoattractant protein [MCP]-1 [MCAF], macrophage inflammatory protein $[\mathrm{MIP}]-1 \alpha, \mathrm{MIP}-1 \beta$, platelet-derived growth factor [PDGF]-bb, regulated on activation normal $\mathrm{T}$ cell expressed and secreted [RANTES] chemokine, tumor necrosis factor [TNF]- $\alpha$ and vascular 
endothelial growth factor [VEGF]). IL-2 detection was included to have an internal positive control. Briefly, $50 \mu \mathrm{L}$ of cytokine standards or samples (supernatants from seeded cells) were incubated with $50 \mu \mathrm{L}$ of anti-cytokine conjugated beads in 96-well plates for $30 \mathrm{~min}$ at room temperature (RT) with shaking. Plates were then washed three times with $100 \mu \mathrm{L}$ of Bio-Plex wash buffer using the Bio-Plex Pro Wash Station (Bio-Rad Laboratories), then $25 \mu \mathrm{L}$ of diluted detection antibody was added and plates were incubated for $30 \mathrm{~min}$ at RT with shaking. After three washes, $50 \mu \mathrm{L}$ of streptavidinphycoerythrin was added, and the plates were incubated for $10 \mathrm{~min}$ at RT with shaking. Finally, plates were washed three times, beads were suspended in Bio-Plex assay buffer and samples were analyzed on Bio-Rad 96-plate reader using the Bio-Plex suspension array system and Bio-Plex manager software (Bio-Rad Laboratories) (24). Secretome of patient-derived CIK cells was compared with those of healthy donors to evaluate possible differences in the secretory pathways.

\section{RNA Extraction and Secretome Gene Expression Profile}

Total cellular RNA was isolated from 3 million PBMCs (d 1, absence of INF- $\gamma$ ) and CIK cells ( $\mathrm{d}$ 14) obtained from 5 GIST patients, using Invitrogen TRIzol (Thermo Fisher Scientific). We performed a microarray analysis of CIK cells at $\mathrm{d}$ 14 instead of $\mathrm{d} 21$ (mature CIK cells) to study gene expression changes during CIK cell maturation. Disposable RNA chips (Agilent RNA 6000 Nano LabChip kit; Agilent Technologies) were used to determine the purity/integrity of RNA samples with an Agilent 2100
Bioanalyzer. NanoDrop ND-1000 spectrophotometer was used to evaluate the RNA sample concentration, and 260/280 $\mathrm{nm}$ and 260/230 nm ratios were considered to verify the purity of total RNA. For microarray analysis, we selected the three RNA sample pairs with the best RNA integrity number. Briefly, cDNA synthesis and biotin-labeled target synthesis were performed using the Gene Atlas 3' IVT Plus Reagent Kit according to the standard protocol supplied by Affymetrix. The HG-U219 Array Strip (Affymetrix, Santa Clara, CA, USA) hybridization, staining and scanning were performed using the GeneAtlas platform.

Gene expression profile data were analyzed with the Partek GS 6.6 software package and normalized using the robust multiarray average procedure (25). Differentially expressed genes (DEGs) were then selected using a supervised approach with the analysis of variance module included in the Partek GS package. In particular, we selected all the probe sets with a fold change contrast $\geq 2$ in the pairwise comparison of CIK cells with PBMCs, and a false discovery rate (q-value) $<0.05$. Ingenuity Pathway Analysis (IPA) (www.ingenuity. com) was used to study cellular processes and pathways modulated in CIK cells.

All microarray data were submitted to the Gene Expression Omnibus repository

(www.ncbi.nlm.nih.gov/geo/query/ acc.cgi?acc $=$ GSE97581).

\section{Statistics}

Results are expressed as mean \pm standard deviation. Comparisons between samples of $\mathrm{d} 14$ and $\mathrm{d} 1$ and between $\mathrm{d} 21$ and $\mathrm{d} 1$ were made by using nonparametric unpaired $t$ test (Mann-Whitney). Differences between groups were considered significant when ${ }^{*} p<0.05$ and highly significant when $* * p<0.01$.

All supplementary materials are available online at www.molmed.org.

\section{RESULTS}

\section{Ex Vivo Expansion and Phenotype of CIK Cells}

CIK cells were successfully generated from five GIST patients starting from cryopreserved PBMCs within 3 wks of culture according to a standard protocol that included timed addition of IFN- $\gamma$, $\mathrm{Ab}$ anti-CD3 OKT3 and IL-2 $(8,9)$. Four out five patients had a diagnosis of advanced-stage GIST, treated with molecular targeted therapy (imatinib $\mathrm{n}=3$, sunitinib $n=1$ ). One patient (PT 3 ) had localized-stage GIST, treated with surgical resection followed by adjuvant therapy with imatinib. The median expansion of bulk patient-derived CIK cells, calculated on the total $\mathrm{CD}^{+}$fraction, was 69 -fold (range 12-191). The median expression of the $\mathrm{CD}^{+} \mathrm{CD}^{2} 6^{+}$cell fraction was $34 \%$ (15-50). The presence of pure NK (CD3 $\mathrm{CD}^{2} 6^{+}$) cells was negligible, median $0.93 \%$ $(0.23-3.8)$ at the end of the expansion. The subset of mature patient-derived CIK cells co-expressing CD3 and CD56 molecules $\left(\mathrm{CD}^{+} \mathrm{CD}^{+} 6^{+}\right)$was present with a median of $34 \%$ (range $15-50$ ), whereas $74 \%$ (45-90) of total bulk CIK cells were $\mathrm{CD}^{+}$. The median membrane expression of the NKG2D receptor on expanded patient-derived CIK cells was $84 \%$ (61\%-96\%). We confirmed the absence of $\mathrm{T}$ regulatory cells within CIK cultures at either d 14 or $d 21(n=2$ : PTs 2 and 4). A summary of patient characteristics and relative CIK cell expansion and phenotypes are reported in Table 1.

Table 1. Characteristics of patients and CIK cells

\begin{tabular}{lcccccccc}
\hline $\begin{array}{c}\text { Age/ } \\
\text { Gender }\end{array}$ & $\begin{array}{c}\text { CD3+CD56+ } \\
\text { Day 0 (\%) }\end{array}$ & $\begin{array}{c}\text { CD3+CD56+ } \\
\text { Day 14 (\%) }\end{array}$ & $\begin{array}{c}\text { CD3+CD56+ } \\
\text { Day 21 (\%) }\end{array}$ & $\begin{array}{c}\text { CD3+ } \\
\text { Day 21 (\%) }\end{array}$ & $\begin{array}{c}\text { CD3+CD8+ } \\
\text { Day 21 (\%) }\end{array}$ & $\begin{array}{c}\text { CD3+NKG2D+ } \\
\text { Day 21 (\%) }\end{array}$ & $\begin{array}{c}\text { Expansion } \\
\text { (Fold) }\end{array}$ \\
\hline PT1 & $59 / \mathrm{F}$ & 3 & 25 & 40 & 99 & 81 & 90 & 119 \\
PT2 & $60 / M$ & 4 & 10 & 19 & 98 & 71 & 76 & 33 \\
PT3 & $64 / M$ & 7 & 32 & 34 & 99 & 59 & 80 & 68 \\
PT4 & $65 / M$ & 4 & 9 & 15 & 99 & 78 & 82 & 191 \\
PT5 & $66 / M$ & 5 & 28 & 33 & 97 & 76 & 88 & 81 \\
\hline
\end{tabular}




\section{Secretome of CIK Cells}

Secretome analysis was performed at specific time points during the threeweek ex vivo expansion: at $\mathrm{d} 1$ on PBMC supernatants collected after $24 \mathrm{~h}$ of culture in the absence of any cytokines; at d 14 on CIK cell cultures; and at d 21 on supernatants of mature CIK cells (see also Materials and Methods). Figure 1 describes the experimental design and shows the complete list of growth factors, chemokines and cytokines analyzed. IL-2 detection was included to have an internal positive control (data not shown).

Mature CIK cells produced multiple soluble factors, including cytokines, chemokines and growth factors. The secreted proteins were schematically divided based on their concentration into three groups: high, medium and low (Figure 2). We found that IL-13 (5054 \pm $2117 \mathrm{pg} / \mathrm{mL})$, RANTES (1244 $\pm 642 \mathrm{pg} /$ $\mathrm{mL}), \mathrm{MIP}-1 \alpha(1755 \pm 1228 \mathrm{pg} / \mathrm{mL})$ and MIP-1 $\beta(30570 \pm 24613 \mathrm{pg} / \mathrm{mL})$ were secreted at high levels (Figure 2A). The medium secreted factors were IL-1Ra $(85 \pm 9 \mathrm{pg} / \mathrm{mL}), \mathrm{IL}-5(741 \pm 174 \mathrm{pg} / \mathrm{mL})$, IL-8 (579 \pm 228 pg/mL), IL-10 (202 \pm 89 $\mathrm{pg} / \mathrm{mL}), \mathrm{IL}-17(115.5 \pm 27 \mathrm{pg} / \mathrm{mL}), \mathrm{IP}-10$ $(518.5 \pm 162 \mathrm{pg} / \mathrm{mL}), \mathrm{INF}-\gamma(893.5 \pm 172$ $\mathrm{pg} / \mathrm{mL}), \operatorname{VEGF}(372 \pm 45 \mathrm{pg} / \mathrm{mL})$ and GMCSF (174 $\pm 51.5 \mathrm{pg} / \mathrm{mL}$ ) (Figure 2B). Finally, IL-1 $\beta(14 \pm 4 \mathrm{pg} / \mathrm{mL})$, IL-4 $(5 \pm 1 \mathrm{pg} / \mathrm{mL}), \mathrm{IL}-6(17 \pm 5 \mathrm{pg} / \mathrm{mL}), \mathrm{IL}-7$ $(2 \pm 0.5 \mathrm{pg} / \mathrm{mL}), \mathrm{IL}-9(17 \pm 4 \mathrm{pg} / \mathrm{mL})$, IL-12 $(8.5 \pm 1$ pg/mL), IL-15 $(4 \pm 1$ pg/mL), eotaxin $(14 \pm 5 \mathrm{pg} / \mathrm{mL})$, PDGF-bb (12 \pm $2 \mathrm{pg} / \mathrm{mL})$, FGF basic $(8 \pm 4 \mathrm{pg} / \mathrm{mL})$, G-CSF $(6 \pm 1 \mathrm{pg} / \mathrm{mL})$ and MCP-1 $(10 \pm 5 \mathrm{pg} / \mathrm{mL})$ secreted at low levels (Figure 2C). The secretion pattern obtained from mature patient-derived CIK cells (d 21) trended similarly to that observed from control CIK cells generated from healthy donors.

To explore the dynamic of CIK cell secretome, the main classes of secreted proteins, i.e., growth factors, cytokines and chemokines, were analyzed at different time points. We compared their release during the ex vivo expansion at

\section{Experimental design}

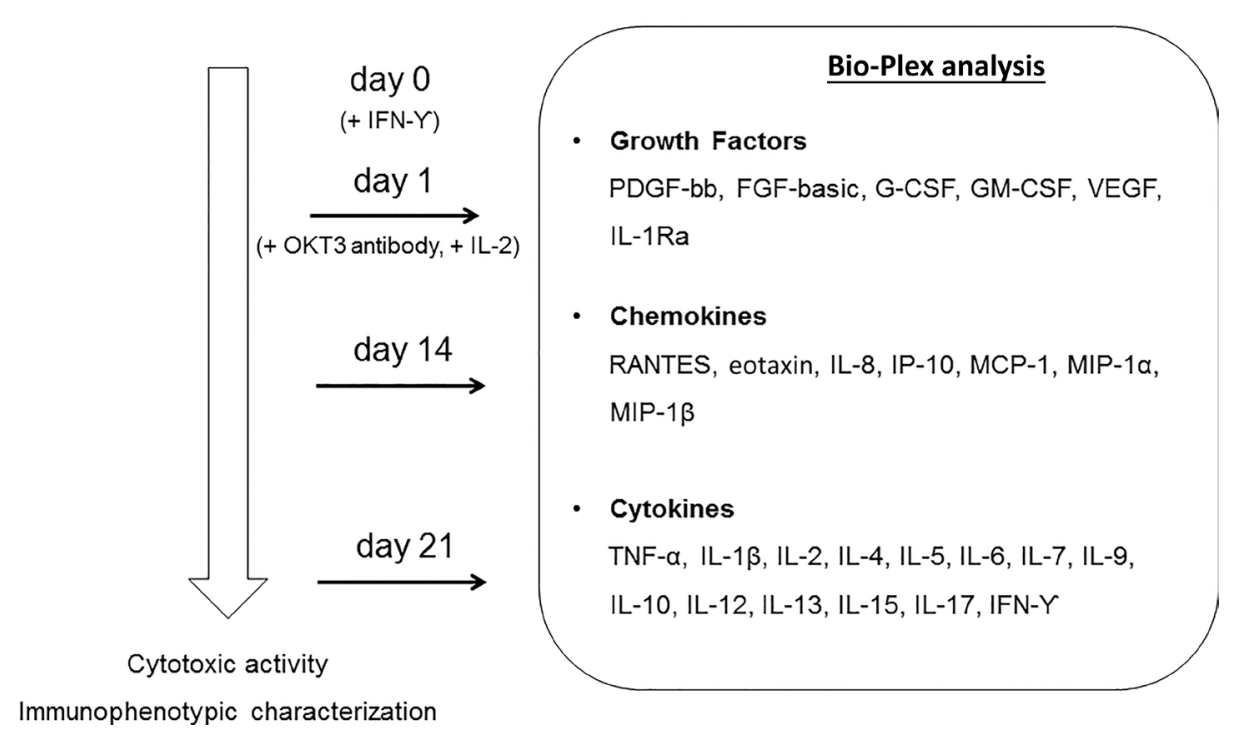

Figure 1. Bio-Plex analysis and experimental design. Secretome analysis was performed on supernatants collected at d 1 (no cytokines), $d 14$ and d 21 of ex vivo expansion of CIK cells. The right panel shows the complete list of growth factors, chemokines and cytokines analyzed by Bio-Plex. IFN- $\gamma(1000 \mathrm{U} / \mathrm{mL})$ was added at $\mathrm{d} 0$, while OKT3 antibody $(50 \mathrm{ng} / \mathrm{mL})$ and $\mathrm{IL}-2(300 \mathrm{U} / \mathrm{mL})$ were added at $\mathrm{d} 1$ and up to the end, refreshing the medium every $2-3 \mathrm{~d}$.

d 1 (as unstimulated PBMCs), d 14 and d 21 (mature CIK cells). We observed that PDGF-bb, IL-1Ra, G-CSF, IL-1 $\beta$, IL-6, IL-8 and $\mathrm{MCP}-1$ were released on $\mathrm{d} 1$, but their levels progressively and intensely decreased by d 14 (Figure 3A). A similar diminishing trend, although less pronounced, was observed for FGF-basic, IL-15, IL-17, eotaxin and RANTES (Figure 3A). On the contrary, the concentrations of GM-CSF, VEGF, IL-5, IL10 and IL-13 progressively increased during the ex vivo expansion of CIK cells (Figure 3B). The concentration levels of IL-4, IL-9 and IL-12 did not significantly vary over time (Figure 3C).

\section{Secretome Gene Expression Profile of CIK Cells}

We investigated the molecular networks activated during the ex vivo expansion of CIK cells. We performed gene expression profiling of RNA obtained from CIK cells collected at specific time points: at d 1 (basal PBMCs) and at d 14 (CIK cells) (see Materials and Methods). PTs 2, 3 and 4 were selected for microarray analysis based on the best RNA integrity number.

The principal component analysis (PCA) (Supplementary Figure S1) shows that the CIK cell samples clustered together and were clearly separated from PBMCs. Next, using an analysis of variance-based supervised approach to compare CIK cells with PBMCs, we identified 3799 DEGs. As shown in Figure 4, hierarchical clustering analysis using the list of DEGs correctly grouped the different cell phenotypes. First, we checked the mRNA expression levels of 27 secreted proteins analyzed by BioPlex assay, and good correspondence between transcriptomic and proteomic profiles was detected. In particular, we confirmed upregulation of GM-CSF, IL-5, IL-10, IL-13 and IFN- $\gamma$ in mature CIK cells. Moreover, consistent with secretome data, IL-1Ra, IL-1 $\beta, I L-6, I L-15, I L-8$, eotaxin (CCL11) and MCP-1 were downregulated in mature $C I K$ cells compared with PBMCs. On the contrary, PDGF-bb, FGF-basic, G-CSF, IL-9 and IP-10 were not significantly modulated (Figure 5). 


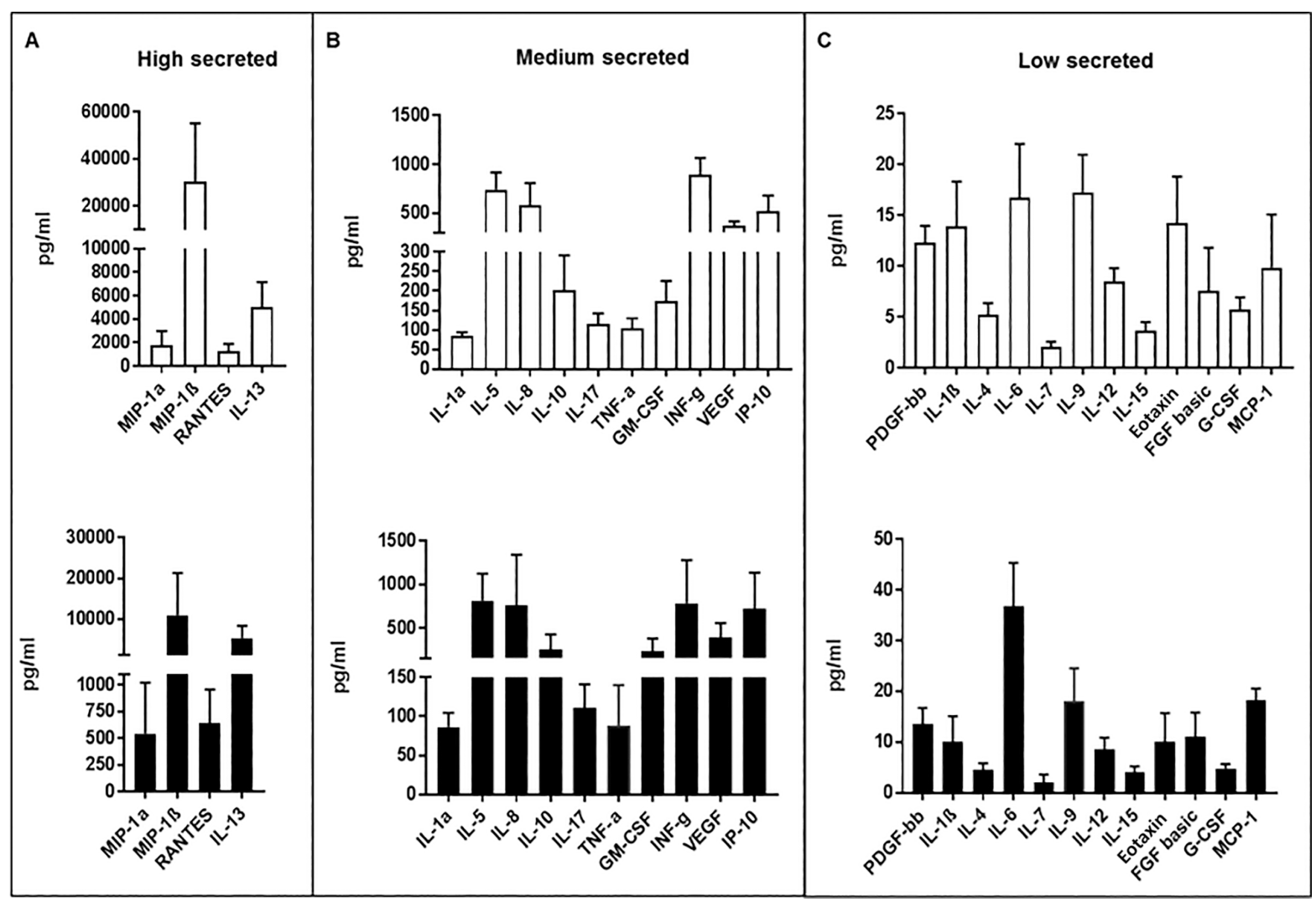

Figure 2. Secretome of mature CIK cells. Secretion of 27 cytokines and cell soluble factors were measured by Bio-Plex cytokine assay on CIK cell supernatants at d 21 of culture. Histograms (white for patients, black for healthy donors) represent mean values \pm standard deviation $(\mathrm{pg} / \mathrm{mL})$ of secreted proteins.

Of note, among DEGs we identified other secreted molecules that were upregulated in mature patient-derived CIK cells, which could contribute to their tumor-killing activity: GZMA, GZMB, GZMK, PRF1, IL-32 and LTA (Supplementary Table S1). Furthermore, as shown in Supplementary Table S2, to better characterize the CIK cell phenotype, we studied the surface antigen expression. As expected, we found downregulation of several myeloid differentiation markers (CD14, CD9, CD93, CSF2RA, CSF2RB, EPB41L3, receptors for $\mathrm{FC}$ fragments of immunoglobulins, ITGAX, MCEMP1 and TREM1) and B cell antigens (CD19, CD24, CD79A, CXCR5 and MS4A1). Moreover, microarray data confirmed upregulation in CIK cells of well-known surface antigens like CD3D, CD3G, IL-2Ra, IL-2RG, CD226/ DNAM1, ITGAL/LFA-1, KLRK1/

\section{NKG2D, NCR3/NKp30 and TRAIL/ TNFSF10.}

Next, to identify differentially expressed pathways during CIK cell maturation, we performed a functional analysis by using IPA software (December 2016 release). Among inactivated functions in CIK cells, we found "chemotaxis of myeloid cells," "phagocytosis," "migration of granulocytes" and "engulfment of leukocytes" (Supplementary Table S3).

Figure 6 shows the modulated expression of genes related to the chemotaxis and phagocytosis processes (panels A and $B$, respectively). Of note, functional gene categories "proliferation of cells," "cell death of lymphocytes," "cell death of mononuclear leukocytes," "apoptosis of B lymphocytes" and "quantity of CD4 ${ }^{+}$T-lymphocytes" were activated, in agreement with the selection and expansion of CIK cell precursors induced by in vitro treatment of PBMCs. In particular, Figure 6C shows the expression of genes that play a pivotal role in $\mathrm{B}$ cell apoptosis. Moreover, IPA analysis predicted as activated categories "cytotoxicity of lymphocytes," "cytotoxicity of cells" and "cytotoxicity of natural killer cells" (Supplementary Table S3). In particular, genes involved in cytotoxic mechanism of CIK cells like NCR3/ NKp30, KLRK1/NKG2D, TRAIL/TNFSF10, CD226/DNAM1, CD244, CD69, CD96, GZMA, GZMB and PRF1 are differently expressed (Figure 6D).

\section{DISCUSSION}

Immune cells play a fundamental role against cancer; however, in many cases tumor cells become able to circumvent the activity of innate and adoptive immune response (26). 


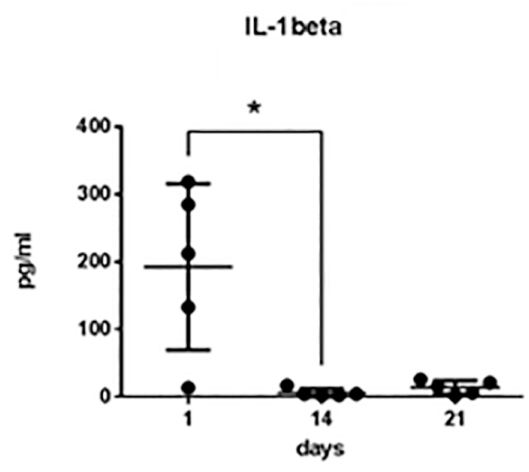

IL-6

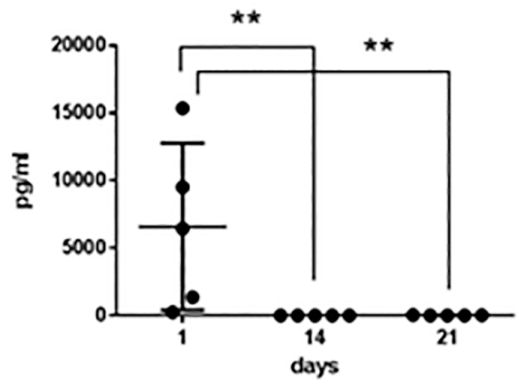

IL-15

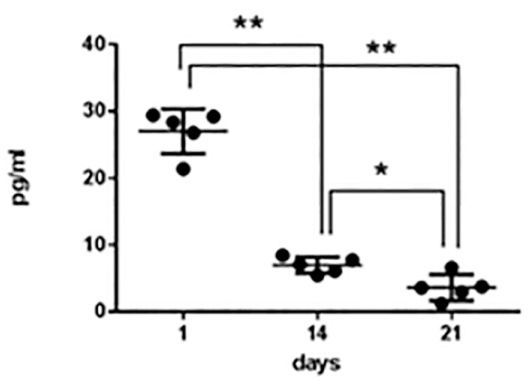

MCP-1

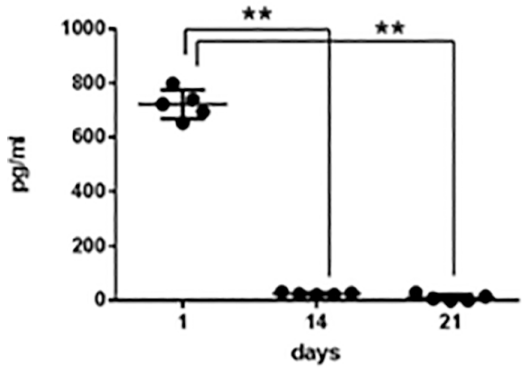

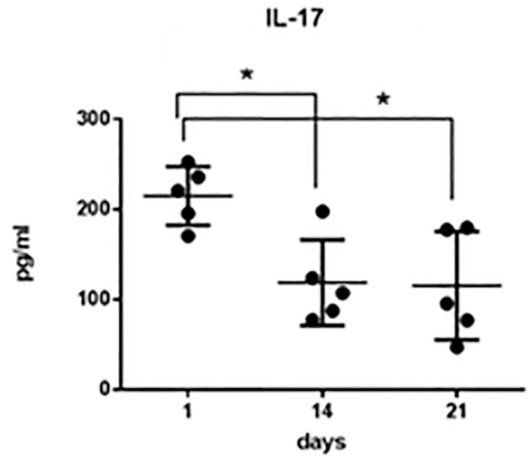

IL-1Ra

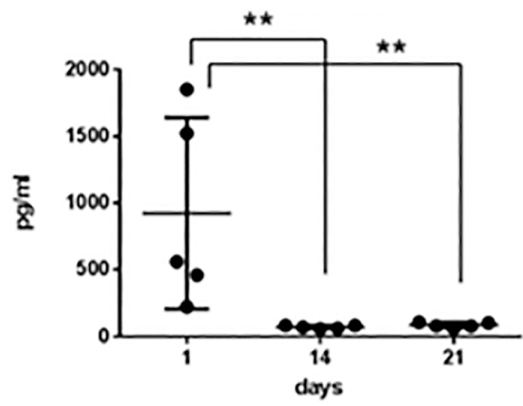

IL-8

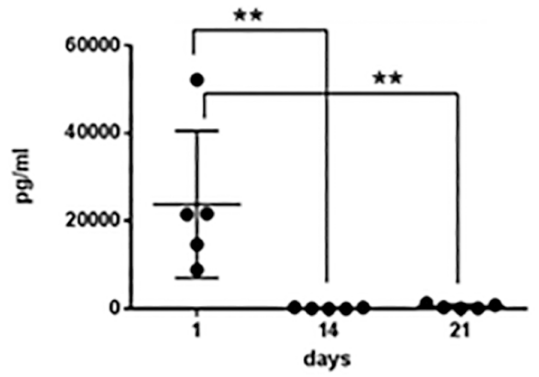

Eotaxin

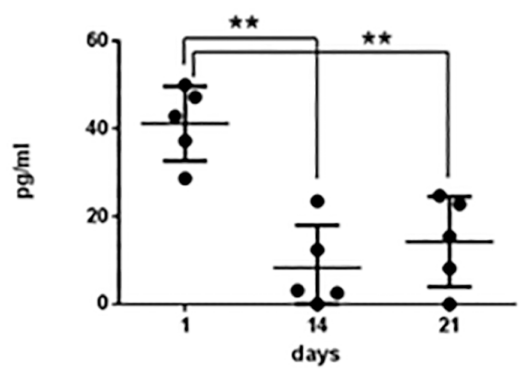

G-CSF

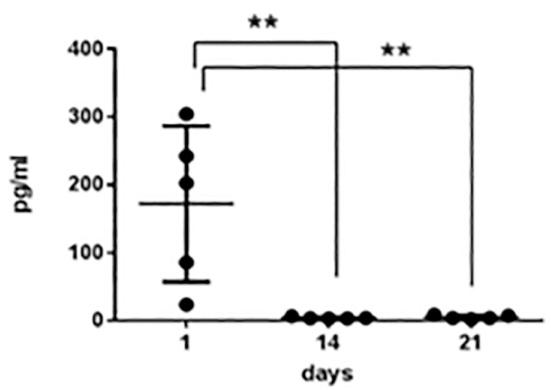

FGF-basic
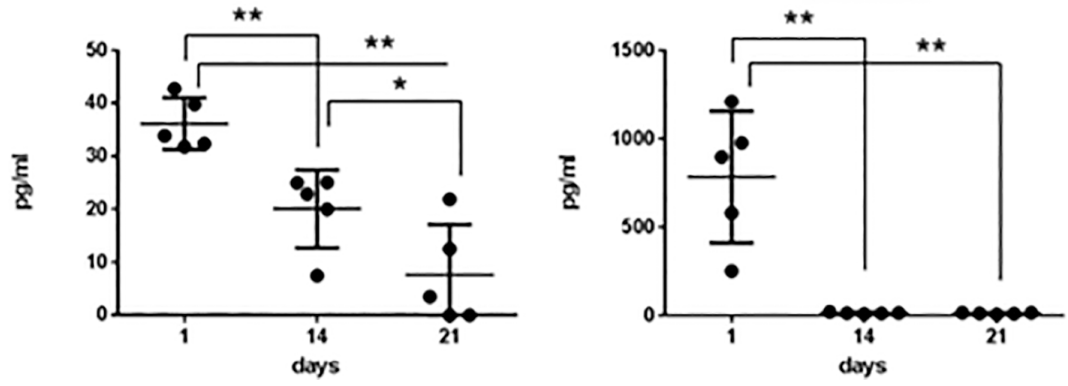

Figure 3. Secretion kinetic of patient-derived CIK cells. Cell culture supernatants were collected at the indicated time points and analyzed by Bio-Plex assay. Differences between groups were considered significant when ${ }^{*} p<0.05$ and highly significant when ${ }^{* *} p<0.01$. 
IL-5

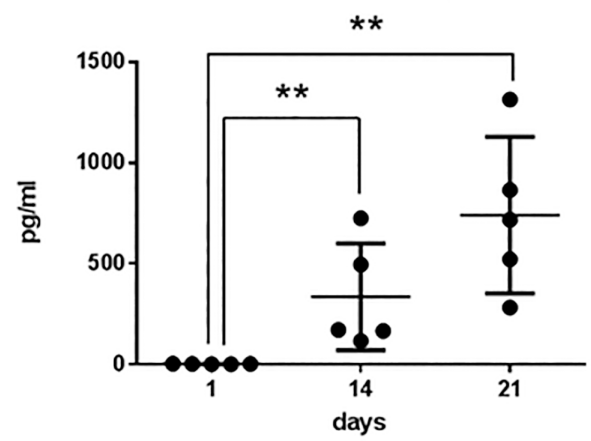

IL-10

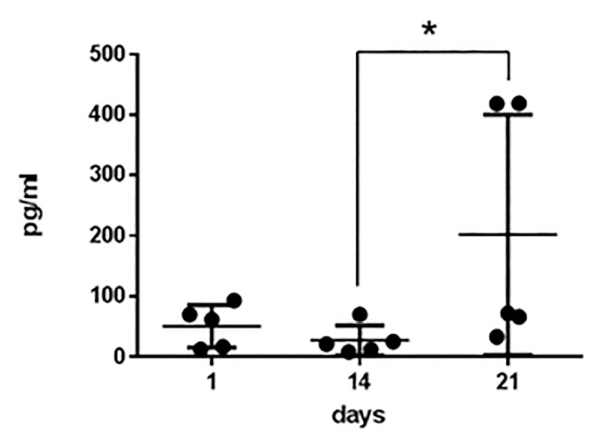

$\mathrm{IL}-13$

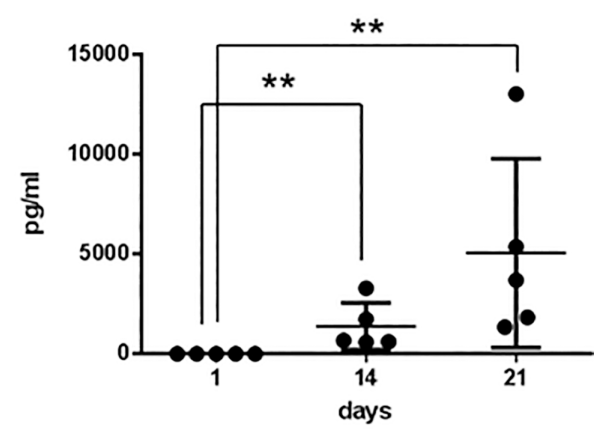

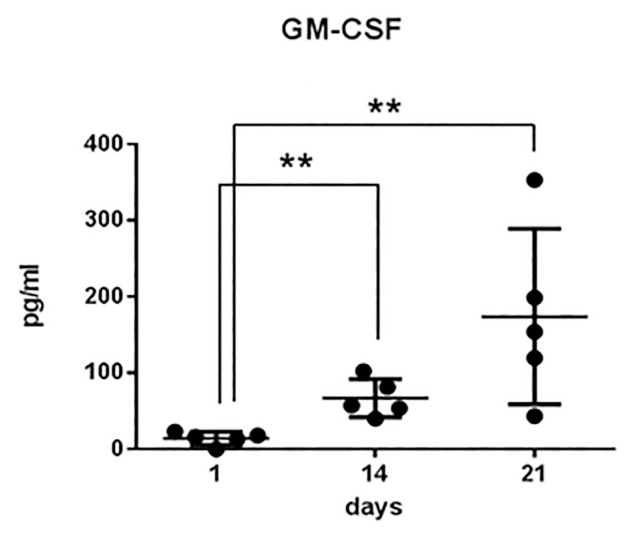

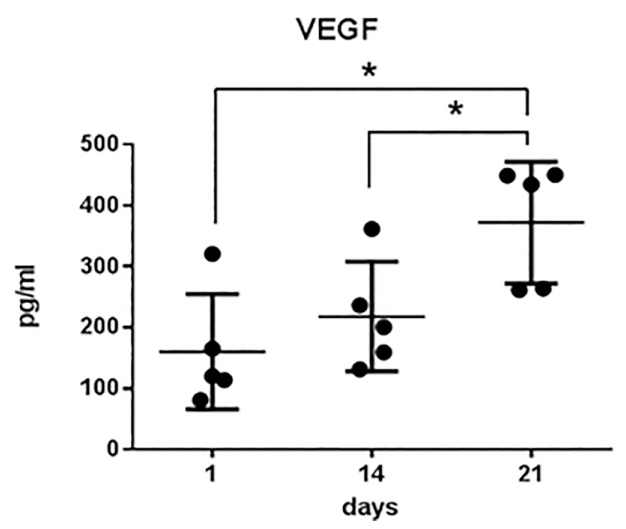

IL-4

IL-9

IL-12 (p70)
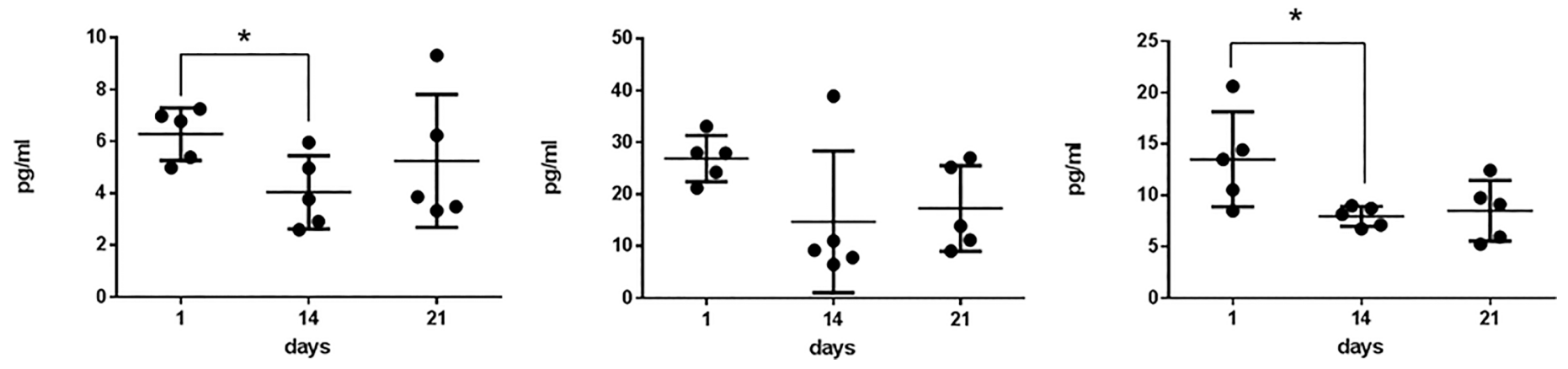

Figure 3. Continued.

Cancer immunotherapy holds great potential against various forms of cancer $(27,28)$, exploiting either antibody or cell-mediated responses. Among adoptive immunotherapy approaches, CIK cells represent an intriguing therapeutic option, since they are endowed with intense MHC-independent antitumor activity against both hematopoietic and solid tumors $(9,29-32)$.
While CIK cells are usually generated by a standard protocol, many efforts are ongoing to enhance their efficacy by exploring new or additional cytokine integrations (33-36).

Identification of cytokines secreted by CIK cells during their differentiation sheds light on mediators that could positively or negatively modulate tumor growth by acting at different levels. An obvious impact of the study is that it provides a rationale to explore the functional implications and possible therapeutic modulation of CIK secretome.

To unravel CIK secretory properties, we undertook a thorough investigation, starting from the first stages of differentiation and ending at $\mathrm{d} 21$, which is the time point of infusion of CIK cells in patients with cancer. We found that 

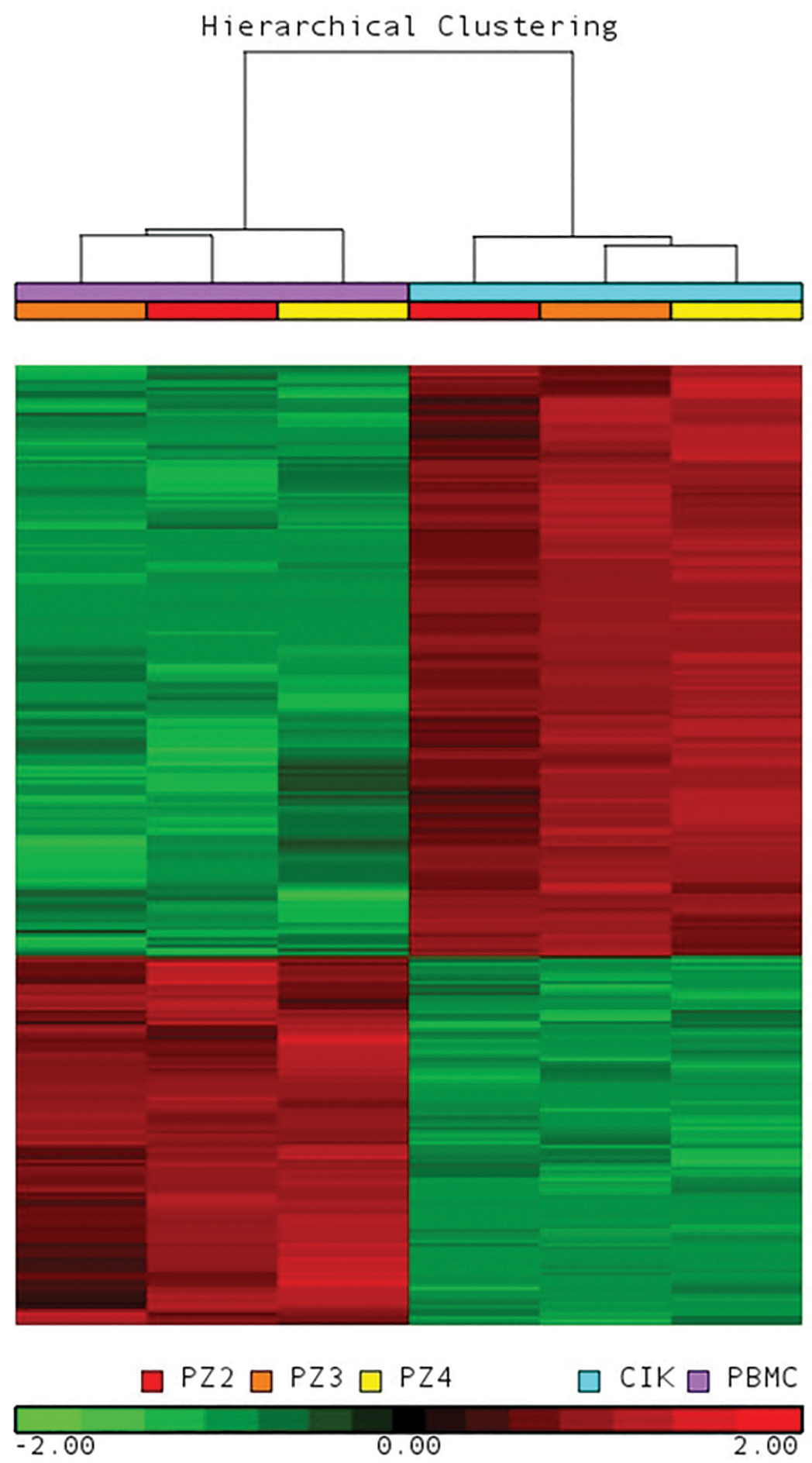

Figure 4. Gene expression profile was analyzed in PBMCs (d 1) and CIK cells (d 14) obtained from three GIST patients. The heat map was computed on the gene list including 3799 DEGs using the clustering algorithm included in the Partek GS package by means of Euclidean distance and average linkage. Gene coloring is based on normalized signals, as shown at the bottom of the figure; green indicates reduced expression, red increased expression. CIK cell and PBMC groups clustered separately in the dendrogram as shown at the top of the heat map.
IL-5, IL-10, IL-13, GM-CSF and VEGF production greatly increased during differentiation, whereas IL-4, IL-9 and IL-12 cytokine secretion levels changed minimally. On the contrary, IL-1 $\beta$, IL-6, IL-8, IL-15, IL-17, eotaxin, MCP-1, IL-1Ra, G-CSF, FGF-basic and PDGF-bb were downregulated over the same time.

GM-CSF mediates a wide variety of effects on cells of the immune system (37). Although GM-CSF is among the growth factors known to promote the expansion of immunosuppressive myeloid-derived suppressor cells (MDSCs), thus promoting tumor growth and metastatic dissemination (38), many reports have also shown relevant positive effects of GM-CSF for immunotherapy $(39,40)$. These include $\mathrm{T}$ cell activation, maturation of dendritic cells and stimulation of humoral and cell-mediated responses (41). Data obtained in mice, using herpes simplex virus armed with GM-CSF, have shown its efficacy against pancreatic cancer (42). Preclinical and clinical studies have shown GM-CSF antitumor activity against melanoma, either alone or in association with antimelanoma vaccines $(43,44)$. GM-CSF represents a successful choice in association with anti-GD2 monoclonal antibodies, also for patients with high-risk neuroblastoma (39).

An interesting observation from CIK cell secretome relates to the very low production of IL-6. Indeed, IL-6 is gaining attention for its role in tumor biology. It has recently been found in tissue samples of human prostate obtained by needle biopsy (45), and an integrated gene and miRNA expression analysis of prostate cancer-associated fibroblasts supports a prominent role for IL-6 in fibroblast activation (46). Moreover, IL6-mediated signaling in hepatocellular carcinoma has been considered crucial for blocking initiation and malignant growth of this neoplastic disease by the anticancer agent icaritin (47). A protective role in hepatocellular carcinoma has been shown for chemerin, also known as retinoic acid receptor responder protein 2, which inhibits IL-6 and GM-CSF expression and MDSC accumulation (48). 


\section{CIK vs. PBMC Fold Change}

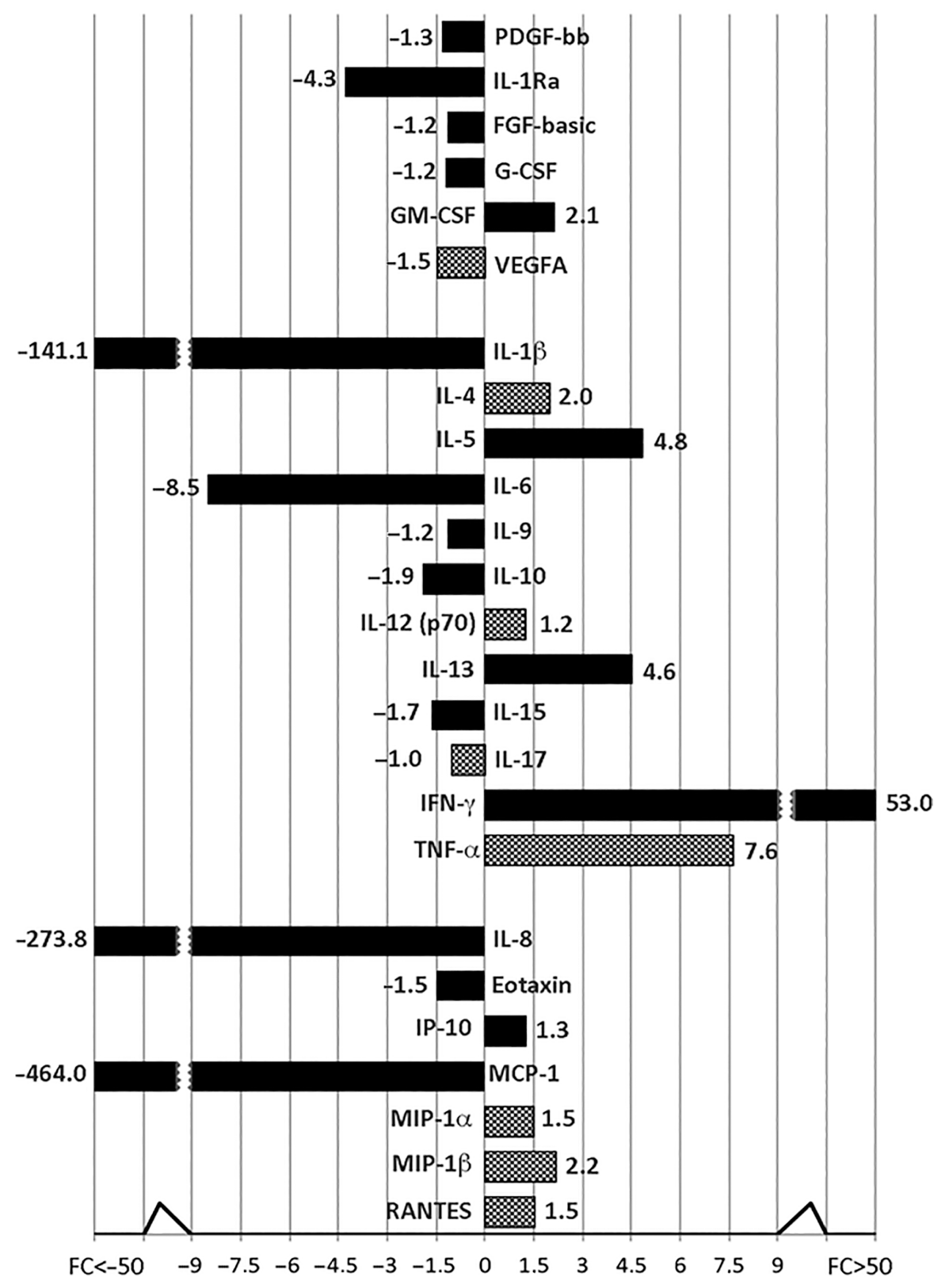

Figure 5. Gene expression profile of CIK cells and correspondence with secretome. mRNA expression was analyzed in PBMCs (d 1) and CIK cells (d 14). Protein levels of secreted proteins previously analyzed by the Bio-Plex platform were compared with the corresponding mRNA expression profile. The black blocks display the mRNA expression data that confirm the secretome analysis results. Instead, the chess pattern displays mRNA expression data that are inconsistent with secretome analysis.

IL-6 is also among those cytokines recently identified as tumor-derived factors inducing CD38 expression in ex vivo MDSCs. Interestingly, highly expressing CD38 MDSCs have an elevated ability to suppress activated $\mathrm{T}$ cells and promote tumor growth (42).

Our analysis shows that human CIK cells secrete another crucial cytokine that has both positive and negative effects depending on tissue context and conditions. IL-10 exerts positive homeostatic effects by downmodulating global immune response, thus preventing tissue damage and chronic inflammation; however, many reports have shown that IL-10 impairs cytotoxic responses of immune cells against tumors (49). Accordingly, elevated IL-10 concentration in serum and cerebrospinal fluid has been linked to poor prognosis in different tumors (50-53), and inhibition of IL-10-mediated signaling increases T cell infiltration and responses against mouse tumors (54). However, recent findings demonstrated that IL-10 in combination with oncolytic virotherapy can enhance pancreatic cancer rejection (55).

Another cytokine playing a role in tumor biology is IL-13. Besides CIK cells, IL-13 is secreted by a variety of cell types, including T helper type 2 lymphocytes, mast cells, basophils, eosinophils, dendritic cells and CD8 ${ }^{+} \mathrm{T}$ lymphocytes (56). It is released upon stimulation by proteases or allergens, thus inducing eosinophilic inflammation and immunoglobulin E class switching in B cells (57). In monocytes and macrophages, IL-13 inhibits the production of prostaglandins, reactive oxygen, nitrogen intermediates and proinflammatory cytokines, among them IL-1, IL-6, IL-8, TNF- $\alpha$ and IL-12 (58). It has been shown that IL-13 exerts multiple effects on tumor cells. Hence, it favors growth of cutaneous T cell lymphoma and its concentration increase correlates with the number of MDSCs in pancreatic, esophageal and gastric cancer. Accordingly, targeting of the IL13Ralpha2 subunit of IL-13R suppresses breast cancer lung metastasis in mice $(59,60)$. Our study shows that IL-13 is highly produced by CIK cells, therefore it would be worthwhile to study in depth the repercussions of CIK-secreted IL-13 on in vitro and in vivo tumor growth. Chemokines play multiple roles in cancer biology and recruitment of cancer responsive immune cells. We also showed that CIK cells produce VEGF during differentiation, giving rise to questions on potential side effects (ie, favor tumor survival and dissemination). The role of VEGF in cancer angiogenic 

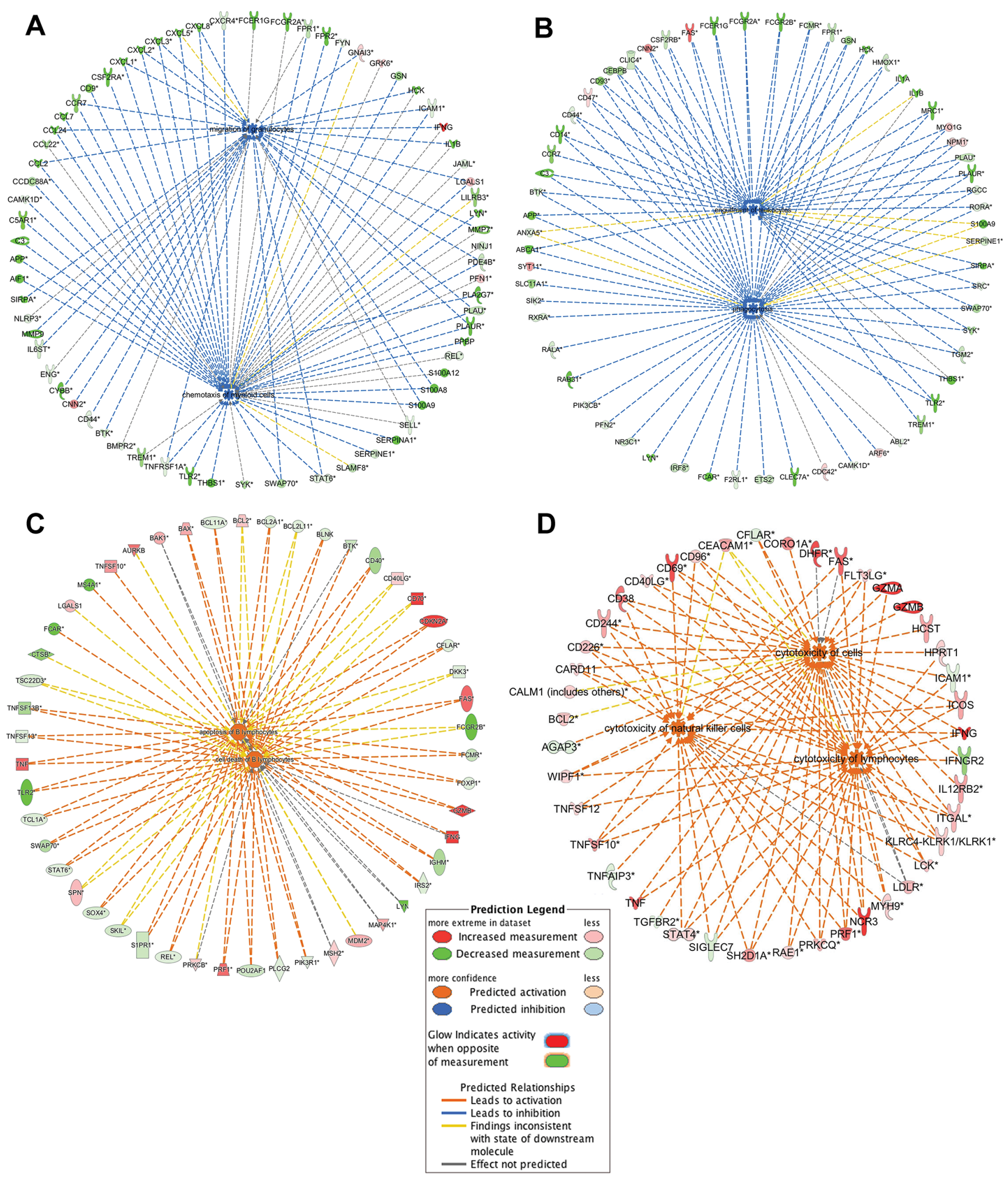

Figure 6. IPA functional analysis of gene expression data from CIK cells discovered different inhibited/activated processes based on the expression pattern of regulatory molecules: (A) chemotaxis, (B) phagocytosis, (C) apoptosis of B lymphocyte, (D) cytotoxicity. The orange lines show that the activation effect of protein was positively confirmed by the IPA Knowledge database. The blue lines show that the inhibitory effect of protein was positively confirmed by the IPA Knowledge database. The gray lines indicate that the proteins lacked literature support to predict the activation effect. The yellow lines indicate that our results and the literature in IPA are not consistent. Solid lines: direct interactions; dashed lines: indirect interactions. 
activity has been deeply investigated, showing that it represents a powerful way for tumors to induce formation of new vessels by both autocrine and paracrine stimulation, thus favoring tumor metastatic dissemination (61). Although the effects of anti-VEGF-based therapy can be transitory (62), VEGF still represents a target for pharmacologically controlling and inhibiting neoangiogenesis and metastatic diffusion $(63,64)$, therefore the previously unknown capacity of CIK cells to secrete this pro-angiogenic factor is relevant (65).

\section{CONCLUSION}

In this report we analyzed the secretory panel of human CIK cells laying a foundation for future studies on modulation of CIK secretome. This will hopefully represent a new way to increase their performance against neoplastic cells and/or contribute to the establishment of a micro-environment of unfavorable conditions for cancer growth.

\section{ACKNOWLEDGMENTS}

This work was supported in part by FPRC ONLUS $5 \times 1000$, Ministero della Salute 2012; Associazione Italiana per la Ricerca sul Cancro (AIRC), project no. 10005 Special Program Molecular Clinical Oncology $5 \times 1000$ to AIRC-Gruppo Italiano Malattie Mieloproliferative, AIRC project no. 15337. DS is the recipient of a grant from Ricerca Finalizzata-Giovani Ricercatori Ministero della Salute (GR-2011-02349197).

\section{DISCLOSURE}

The authors have no competing interests as defined by Molecular Medicine or other interests that might be perceived to influence the results and discussion reported in this paper.

\section{REFERENCES}

1. Lu PH, Negrin RS. (1994) A novel population of expanded human CD3+CD56+ cells derived from $\mathrm{T}$ cells with potent in vivo antitumor activity in mice with severe combined immunodeficiency. J. Immunol. 153:1687-96.

2. Schmidt-Wolf IG, et al. (1994) Propagation of large numbers of $\mathrm{T}$ cells with natural killer cell markers. Br. J. Haematol. 87:453-58.
3. Baker J, Verneris MR, Ito M, Shizuru JA, Negrin RS. (2001) Expansion of cytolytic CD8(+) natural killer T cells with limited capacity for graftversus-host disease induction due to interferon gamma production. Blood. 97:2923-31.

4. Verneris MR, Karami M, Baker J, Jayaswal A, Negrin RS. (2004) Role of NKG2D signaling in the cytotoxicity of activated and expanded CD8+ T cells. Blood. 103:3065-72.

5. Olioso P, et al. (2009) Immunotherapy with cytokine induced killer cells in solid and hematopoietic tumours: a pilot clinical trial. Hematol. Oncol. 27(3):130-39.

6. Schmidt-Wolf IG, et al. (1999) Phase I clinical study applying autologous immunological effector cells transfected with the interleukin-2 gene in patients with metastatic renal cancer, colorectal cancer and lymphoma. Br. J. Cancer. 81:1009-16.

7. Schmidt-Wolf IG, Negrin RS, Kiem HP, Blume KG, Weissman IL. (1991) Use of a SCID mouse/ human lymphoma model to evaluate cytokine-induced killer cells with potent antitumor cell activity. J. Exp. Med. 174:139-49.

8. Gammaitoni L, et al. (2013) Effective activity of cytokine induced killer cells against autologous metastatic melanoma including cells with stemness features. Clin. Cancer Res. 19(16):4347-58

9. Sangiolo D, et al. (2014) Cytokine-induced killer cells eradicate bone and soft-tissue sarcomas. Cancer Res. 74:119-29.

10. Schmeel LC, Schmeel FC, Coch C, Schmidt-Wolf IG. (2014) Cytokine-induced killer (CIK) cells in cancer immunotherapy: report of the international registry on CIK cells (IRCC). J. Cancer Res. Clin Oncol. 141(5):839-49.

11. Franceschetti M, et al. (2009) Cytokine-induced killer cells are terminally differentiated activated CD8 cytotoxic T-EMRA lymphocytes. Exp. Hematol. 37:616-28.

12. Sangiolo D, et al. (2008) Alloreactivity and anti-tumor activity segregate within two distinct subsets of cytokine-induced killer (CIK) cells: implications for their infusion across major HLA barriers. Int. Immunol. 20:841-48.

13. Pievani A, et al. (2011) Dual-functional capability of CD3+CD56+ CIK cells, a T-cell subset that acquires NK function and retains TCR-mediated specific cytotoxicity. Blood. 118:3301-10.

14. Verneris MR, Baker J, Edinger M, Negrin RS. (2002) Studies of ex vivo activated and expanded CD8+ NK-T cells in humans and mice. J. Clin. Immunol. 22:131-36.

15. Jamieson AM, et al. (2002) The role of the NKG2D immunoreceptor in immune cell activation and natural killing. Immunity. 17:19-29.

16. Diefenbach A, Jamieson AM, Liu SD, Shastri N, Raulet DH. (2000) Ligands for the murine NKG2D receptor: expression by tumor cells and activation of NK cells and macrophages. Nat. Immunol. 1:119-26.

17. Cosman D, et al. (2001) ULBPs, novel MHC class I-related molecules, bind to CMV glycoprotein
UL16 and stimulate NK cytotoxicity through the NKG2D receptor. Immunity. 14:123-33.

18. Groh V, et al. (1999) Broad tumor-associated expression and recognition by tumor-derived gamma delta T cells of MICA and MICB. Proc. Natl. Acad. Sci. USA. 96:6879-84.

19. Jäkel CE, Schmidt-Wolf IG. (2014) An update on new adoptive immunotherapy strategies for solid tumors with cytokine-induced killer cells. Expert Opin. Biol. Ther. 14:905-16.

20. Linn YC, Hui KM. (2010) Cytokine-induced NK-like T cells: from bench to bedside. J. Biomed. Biotechnol. 2010:435745.

21. Zhu BQ, Ju SW, Shu YQ. (2009) CD137 enhances cytotoxicity of CD3(+)CD56(+) cells and their capacities to induce CD4(+) Th1 responses. Biomed. Pharmacother. 63:509-16.

22. $\mathrm{Li} \mathrm{H}$, et al. (2007) CD4+CD25 + regulatory T cells decreased the antitumor activity of cytokine-induced killer (CIK) cells of lung cancer patients. J. Clin. Immunol. 27:317-26.

23. Hombach AA, Rappl G, Abken H. (2013) Arming cytokine-induced killer cells with chimeric antigen receptors: CD28 outperforms combined CD28-OX40 “super-stimulation." Mol. Ther. 21:2268-77.

24. Penolazzi L, et al. (2008) Evaluation of chemokine and cytokine profiles in osteoblast progenitors from umbilical cord blood stem cells by BIOPLEX technology. Cell Biol. Int. 32:320-25.

25. Irizarry RA, et al. (2003) Exploration, normalization, and summaries of high density oligonucleotide array probe level data. Biostatistics. 4:249-64.

26. Vesely MD, Kershaw MH, Schreiber RD, Smyth MJ. (2011) Natural innate and adaptive immunity to cancer. Annu. Rev. Immunol. 29:235-71.

27. Grierson P, Lim KH, Amin M. (2017) Immunotherapy in gastrointestinal cancers. J. Gastrointest. Oncol. 8:474-84.

28. Kumai T, Fan A, Harabuchi Y, Celis E. (2017) Cancer immunotherapy: moving forward with peptide T cell vaccines. Curr. Opin. Immunol. 47:57-63.

29. Mesiano G, et al. (2012) Cytokine-induced killer (CIK) cells as feasible and effective adoptive immunotherapy for the treatment of solid tumors. Expert Opin. Biol. Ther. 12:673-84.

30. Introna M, Golay J, Rambaldi A. (2013) Cytokine induced killer (CIK) cells for the treatment of haematological neoplasms. Immunol. Lett. 155:27-30.

31. Wong E, Ritchie DS, Davis JE. (2016) CIK immunotherapy in refractory hematologic malignancies. Leuk. Res. 49:60-61.

32. Li R, et al. (2012) Autologous cytokine-induced killer cell immunotherapy in lung cancer: a phase II clinical study. Cancer Immunol. Immunother. 61:2125-33.

33. Jiang J, Wu C, Lu B. (2013) Cytokine-induced killer cells promote antitumor immunity. J. Transl. Med. 11:83.

34. Rettinger E, et al. (2012) The cytotoxic potential of interleukin-15-stimulated cytokine-induced killer cells against leukemia cells. Cytotherapy. 14:91-103. 
35. Tao Q, et al. (2013) IL-15 improves the cytotoxicity of cytokine-induced killer cells against leukemia cells by upregulating CD3+CD56+ cells and downregulating regulatory $\mathrm{T}$ cells as well as IL-35. J. Immunother. 36:462-67.

36. Iudicone $P$, et al. (2016) Interleukin-15 enhances cytokine induced killer (CIK) cytotoxic potential against epithelial cancer cell lines via an innate pathway. Hum. Immunol. 77:1239-47.

37. Becher B, Tugues S, Greter M. (2016) GM-CSF: From growth factor to central mediator of tissue inflammation. Immunity. 45:963-73.

38. Chiodoni C, Sangaletti S, Colombo MP. (2017) Matricellular proteins tune myeloid-derived suppressor cell recruitment and function in breast cancer. J. Leukoc. Biol. 102(2):287-92.

39. Cheung IY, Hsu K, Cheung NK. (2012) Activation of peripheral-blood granulocytes is strongly correlated with patient outcome after immunotherapy with anti-GD2 monoclonal antibody and granulocyte-macrophage colony-stimulating factor. J. Clin. Oncol. 30:426-32.

40. Wei XX, et al. (2016) Systemic GM-CSF recruits effector $\mathrm{T}$ cells into the tumor microenvironment in localized prostate cancer. Cancer Immunol. Res. 4:948-58.

41. Sakamoto C, et al. (2017) Therapeutic vaccination based on side population cells transduced by the granulocyte-macrophage colony-stimulating factor gene elicits potent antitumor immunity. Cancer Gene Ther. 24(4)165-74.

42. Liu $\mathrm{H}$, et al. (2013) Preclinical evaluation of herpes simplex virus armed with granulocyte-macrophage colony-stimulating factor in pancreatic carcinoma. World J. Gastroenterol. 19:5138-43.

43. Grotz TE, Kottschade L, Pavey ES, Markovic SN, Jakub JW. (2014) Adjuvant GM-CSF improves survival in high-risk stage IIIc melanoma: a single-center study. Am. J. Clin. Oncol. 37:467-72.

44. Kaufman HL, Ruby CE, Hughes T, Slingluff CL. (2014) Current status of granulocyte-macrophage colony-stimulating factor in the immunotherapy of melanoma. J. Immunother. Cancer. 2:11.

45. Miličević N, Mrčela M, Galić J, Marjanović K. (2015) Expression of proinflammatory cytokine interleukin-6 in tissue samples of human prostate obtained by needle biopsy. Pathol. Res. Pract. 211:865-70.

46. Doldi V, et al. (2015) Integrated gene and miRNA expression analysis of prostate cancer associated fibroblasts supports a prominent role for interleukin-6 in fibroblast activation. Oncotarget. 6:31441-60.

47. Zhao $\mathrm{H}$, et al. (2015) A novel anti-cancer agent Icaritin suppresses hepatocellular carcinoma initiation and malignant growth through the IL-6/ Jak2/Stat3 pathway. Oncotarget. 6:31927-43.

48. Lin Y, et al. (2017) Chemerin has a protective role in hepatocellular carcinoma by inhibiting the expression of IL-6 and GM-CSF and MDSC accumulation. Oncogene. 36(25):3599-3608.

49. García-Rocha R, et al. (2015) Mesenchymal stromal cells derived from cervical cancer tumors induce TGF- $\beta 1$ expression and IL-10 expression and secretion in the cervical cancer cells, resulting in protection from cytotoxic $\mathrm{T}$ cell activity. Cytokine. 76:382-90.

50. Zhao S, Wu D, Wu P, Wang Z, Huang J. (2015) Serum IL-10 predicts worse outcome in cancer patients: a meta-analysis. PLoS One. 10: e0139598.

51. Wang $\mathrm{H}$, et al. (2015) Increased serum levels of interleukin-10 predict poor prognosis in extranodal natural killer/T-cell lymphoma patients receiving asparaginase-based chemotherapy. Onco. Targets Ther. 8:2589-99.

52. Sasayama T, et al. (2016) Tumor-associated macrophages associate with cerebrospinal fluid interleukin-10 and survival in primary central nervous system lymphoma (PCNSL). Brain Pathol. 26:479-87.

53. Dwivedi S, et al. (2015) Functional genetic variability at promoters of pro-(IL-18) and anti-(IL-10) inflammatory affects their mRNA expression and survival in prostate carcinoma patients: five year follow-up study. Prostate. 75:1737-46.

54. Chen S, et al. (2016) Blocking IL-10 signalling at the time of immunization renders the tumour more accessible to $\mathrm{T}$ cell infiltration in mice. Cell Immunol. 300:9-17.

55. Chard LS, Lemoine NR, Wang Y. (2015) New role of interleukin-10 in enhancing the antitumor efficacy of oncolytic vaccinia virus for treatment of pancreatic cancer. Oncoimmunology. 4:e1038689.

56. Wills-Karp M, et al. (1998) Interleukin-13: central mediator of allergic asthma. Science. 282:2258-61.

57. Guo L, et al. (2015) Innate immunological function of TH2 cells in vivo. Nat. Immunol. 16:1051-59.

58. Minty A, et al. (1993) Interleukin-13 is a new human lymphokine regulating inflammatory and immune responses. Nature. 362:248-50.

59. Wasik MA. (2015) IL-13 as a novel growth factor in CTCL. Blood. 125:2737-38.

60. Gabitass RF, Annels NE, Stocken DD, Pandha HA, Middleton GW. (2011) Elevated myeloid-derived suppressor cells in pancreatic, esophageal and gastric cancer are an independent prognostic factor and are associated with significant elevation of the Th2 cytokine interleukin-13. Cancer Immunol. Immunother. 60:1419-30.

61. Quail DF, Joyce JA. (2013) Microenvironmental regulation of tumor progression and metastasis. Nat. Med. 19:1423-37.

62. Shinkaruk S, Bayle M, Laïn G, Déléris G. (2003) Vascular endothelial cell growth factor (VEGF), an emerging target for cancer chemotherapy. Curr. Med. Chem. Anticancer Agents. 3:95-117.

63. Bergers G, Hanahan D. (2008) Modes of resistance to anti-angiogenic therapy. Nat. Rev. Cancer. 8:592-603.

64. Heath VL, Bicknell R. (2009) Anticancer strategies involving the vasculature. Nat. Rev. Clin. Oncol. 6:395-404.

65. Gensicka M, Głowacka A, Dzierzbicka K, Cholewinski G. (2015) Inhibitors of angiogenesis in cancer therapy: synthesis and biological activity. Curr. Med. Chem. 22:3830-47.
Cite this article as: Mesiano G, et al. (2017) Analytic and dynamic secretory profile of patient-derived cytokine-induced killer cells. Mol. Med. 23:235-46. 